\title{
Aortoiliac occlusive disease, a silent syndrome
}

\author{
Sonia Pilar Rodríguez, ${ }^{\oplus 1}$ Felipe Sandoval ${ }^{2}$
}

Epidemiology Department, Universidad Del Rosario, Bogota, Colombia ${ }^{2}$ General Medicine, Clinica Nueva, Bogotá, Colombia

\section{Correspondence to} Dr Sonia Pilar Rodríguez, rocosopi@gmail.com

Accepted 28 June 2019
Check for updates

(C) BMJ Publishing Group Limited 2019. No commercial re-use. See rights and permissions. Published by BMJ.

\begin{tabular}{l}
\hline To cite: Rodríguez SP, \\
Sandoval F. BMJ Case \\
Rep 2019;12:e230770. \\
doi:10.1136/bcr-2019- \\
230770
\end{tabular}

\section{DESCRIPTION}

A 68-year-old woman with a 25.5 pack/year history of smoking consulted the emergency room for acute pelvis and oppressive lumbar pain. Symptoms began 6 months earlier with lower limbs mild pain, intermittent claudication and hypoesthesia. Two months earlier, a venous Doppler ultrasound was performed with normal findings. In the physical examination at the emergency room, no mention was made about lower extremities' pulses. The patient did not consume medicines or report a history of diabetes or hyperlipidaemia.

Due to pain characteristics, an abdominal CT with intravenous and oral contrast was performed. Tomography revealed complete occlusion of the infrarenal abdominal aorta extended to the common and proximal external iliac arteries. Distal iliac arteries were perfused by lumbar and abdominal wall collateral circulation (figure 1). A complementary arterial doppler was performed, depicting 'tardus parvus' waveforms in distal iliac arteries (figure 2). With the diagnosis of aortoiliac occlusive disease, the patient was referred to another institution for treatment.

Aortoiliac occlusive disease, also known as Leriche syndrome, is a progressive atherosclerotic disease that affects the abdominal aorta and iliac arteries. Risk factors include hypertension, hyperglycaemia, hyperlipidaemia, nicotine, age, gender and family history. The classic clinical presentation is bilateral buttock claudication, decreased femoral pulses and sexual dysfunction. ${ }^{1}$

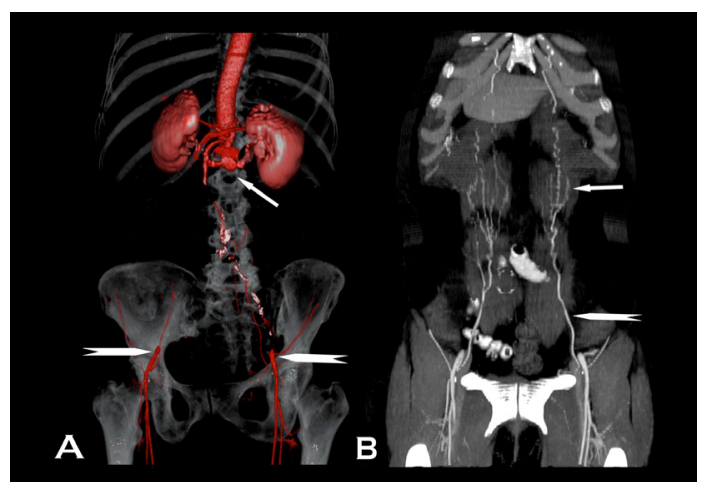

Figure 1 Coronal tomographic reconstructions in arterial phase show (A) Complete occlusion of the infrarenal abdominal aorta (thin arrow). Some atheroma plaques are depicted distal to the occluded segment. External iliac arteries (thick arrows) are perfused by collaterals. (B) Robust anastomosis are seen between inferior and superior epigastric arteries (thin arrow). Significant collateral circulation is detected in inferior epigastric arteries (thick arrow).

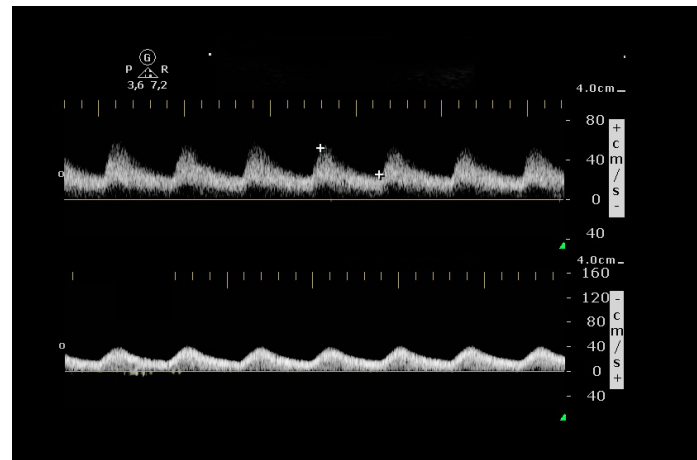

Figure 2 Doppler waveform of right and left external iliac arteries reveals decreased systolic velocities, increased acceleration times and peripheral vasodilatation. This pattern is called 'tardus parvus' and indicates the presence of a clinically significant proximal obstruction.

Since the occlusion occurs progressively, effective collateral pathways have time to develop. Collateral circulation arises from systemic or visceral vessels. The most common systemic path collects flow from lumbar, iliolumbar, sacral and inferior epigastric arteries to nourish the ascending branches of the deep circumflex iliac arteries, reconstituting the patency of external iliac arteries. The essential visceral pathway drifts the flow from the distal superior mesenteric artery to the inferior mesenteric artery branches. Collaterals from the superior mesenteric artery may also anastomose with the rectal plexus to nourish the internal iliac artery. ${ }^{2}$

Aortoiliac occlusive disease diagnosis is made with CT angiography or with conventional angiography. Angiographic images allow defining the site of obstruction, its length, collateral circulation and distal permeability. ${ }^{2}$ The finding of a 'tardus parvus' waveform in arterial Doppler ultrasound when assessing the common femoral arteries or the external iliac arteries is indicative of severe proximal obstruction, making it necessary to perform angiographic studies to exclude aortoiliac occlusive disease. ${ }^{3}$ Venous Doppler ultrasound has no application in the diagnosis of arterial disease.

The treatment that has shown better long-term results is the aortobifemoral bypass. In the last two decades, the implementation of endovascular techniques to reperfuse occluded arteries has shown superior results, reducing the surgical time, morbidity and mortality. The covered endovascular reconstruction of the aortic bifurcation technique uses an endovascular approach to place three covered stents in the aortic bifurcation. This technique has demonstrated short-term superiority over the traditional aortobifemoral grafts, highlighting that the first one allows the treatment of patients 
with more comorbidities and with more complex stenosis. ${ }^{4}$ The survival rate of patients with aortoiliac occlusive disease is determined by the surgical success, the long-term permeability of the graft, the control of risk factors and cessation of tobacco consumption, among others. ${ }^{5}$

\section{Learning points}

- Aortoiliac occlusive disease has a slow progression, which allows the development of effective collateral pathways, having as a consequence the development of mild and insidious symptoms.

- When occlusive arterial disease of the lower limbs is suspected, it is essential to evaluate femoral and tibial pulses at physical examination.

- Consider that CT angiography and arterial Doppler are available in most emergency departments which allow a prompt and accurate diagnosis.
Contributors SPR reviewed the images, performed the Doppler and contributed to the composition of the manuscript. FS contributed to the composition of the manuscript and was in charge of informed consent.

Funding The authors have not declared a specific grant for this research from any funding agency in the public, commercial or not-for-profit sectors.

Competing interests None declared.

Patient consent for publication Obtained.

Provenance and peer review Not commissioned; externally peer reviewed.

\section{REFERENCES}

1 Brown KN, Gonzalez L. Leriche syndrome. In: StatPearls. Treasure Island (FL: StatPearls Publishing, 2019.

2 Ahmed S, Raman SP, Fishman EK. CT angiography and 3D imaging in aortoiliac occlusive disease: collateral pathways in Leriche syndrome. Abdom Radiol 2017:42:2346-57

3 Spronk S, den Hoed PT, de Jonge LC, et al. Value of the duplex waveform at the common femoral artery for diagnosing obstructive aortoiliac disease. J Vasc Surg 2005:42:236-42.

4 Taeymans K, Groot Jebbink E, Holewijn S, et al. Three-year outcome of the covered endovascular reconstruction of the aortic bifurcation technique for aortoiliac occlusive disease. J Vasc Surg 2018;67:1438-47.

5 Thomas AT, Leitman IM. Predictors of serious morbidity and mortality after endovascular repair of aortoiliac lesions. Surgery 2018;164:365-9.

Copyright 2019 BMJ Publishing Group. All rights reserved. For permission to reuse any of this content visit

https://www.bmj.com/company/products-services/rights-and-licensing/permissions/

BMJ Case Report Fellows may re-use this article for personal use and teaching without any further permission.

Become a Fellow of BMJ Case Reports today and you can:

- Submit as many cases as you like

- Enjoy fast sympathetic peer review and rapid publication of accepted articles

- Access all the published articles

- Re-use any of the published material for personal use and teaching without further permission

Customer Service

If you have any further queries about your subscription, please contact our customer services team on +44 (0) 2071111105 or via email at support@bmj.com.

Visit casereports.bmj.com for more articles like this and to become a Fellow 